\title{
Linguistic Structure and Narrative Quality in Child L1 Production
}

\author{
lanthi Maria Tsimpli ${ }^{1}$, Maria Papakonstantinou ${ }^{1}$ \\ and Ageliki Nicolopoulou ${ }^{2}$ \\ ${ }^{1}$ Aristotle University of Thessaloniki, ${ }^{2}$ Lehigh University \\ imt@enl.auth.gr,mpapakon@enl.auth.gr, agn3@lehigh.edu
}

\begin{abstract}
The study investigates the development of referential functions in the use of linguistic forms encoding character Reference with the use of qualitative and quantitative measures in children's narratives. The link between memory scores and narrative performance is also examined. A story telling task presented in two alternative methods of story presentation (booklet vs. card) was used. Four age groups of Typically Developing (TD) Greek children participated. The results on character Reference show a priority in the acquisition of the linguistic forms associated with the function of character Maintenance compared to character Introduction. The method of story presentation seems to affect Length of the narrative as well as the frequency of Coordination and Subordination structures. Finally, some effects of working memory scores are shown in narrative competence.
\end{abstract}

\section{Introduction}

Narrative discourse can indicate cognitive and linguistic development. This is so since anaphoric strategies such as character introduction and maintenance but also cognitive mechanisms such as the ability to construct episodes in a particular order and build a mental model of the narrative are all involved in creating a coherent narrative. At the same time, Theory of Mind (ToM), i.e. the ability to consider the listener's point of view in narrative production is also instrumental in good narrative abilities (Chafe, 1976).

More precisely, the development of narratives is associated with the acquisition of referential functions (e.g. character introduction and maintenance), since the given/new opposition is a universal principle of discourse organization (Vion \& Colas, 1999; Hickmann \& Hendriks, 1999). Other linguistic markers of narrative development such as the use of co-ordination

(cc) BY-NC-ND 
and subordination of phrases and clauses may also be used to evaluate narrative development. Although these properties are primarily linguistic, they are also sensitive to the child's ability to create a story structure. It has been shown that coordination typically precedes subordination in narrative discourse development (cf. de Villiers, 1982).

Turning to character reference, languages differ in the mechanisms they employ to introduce and maintain reference to a character in a narrative. In languages which make a definite/indefinite distinction, a referent mentioned for the first time in discourse is introduced with an indefinite nominal (1). Character maintenance, on the other hand, usually employs a definite nominal (2a), or a pronominal (2b). In null subject languages, such as Greek, character maintenance may involve the use of a null pronominal subject (2c).

(1) Mia fora ki enankerozuse enas lagos.

once upon and a time live- ${ }_{\text {PAST-3s }}$ a hare- ${ }_{\text {SING-NOM }}$

"Once upon a time there lived $\underline{a}$ hare"

(2a) Mia mera $o$ lagos pige na mazepsi karota.

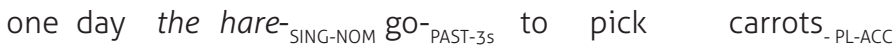

(2b) Mia mera aftos pige na mazepsi karota.

one day it go- ${ }_{\text {PAST-3s }}$ to pick carrots- ${ }_{\text {PL-ACC }}$

(2c) Mia mera propige na mazepsi karota.

one day go- ${ }_{\text {PAST-3s }}$ to pick carrots- ${ }_{\text {PL-ACC }}$

All options in (2a-c) are grammatical and acceptable and all express the referential function of character maintenance.

\section{Previous Studies}

Previous studies on narrative development report that children are better at maintaining than introducing a new referent (Hickman et al, 1996; Wang \& Johnston, 2003). Other studies observed sensitivity to reference continuity vs. discontinuity from the age of 4 years (Hickman \& Schneider, 1993; Hickman $\&$ Hendriks, 1999). Previous studies on the development of subordination in Greek narratives focus on the distinction between temporal and non-temporal adverbials (Kantzou, 2010; Kati \& Kantzou, 2004), but do not deal with the development of referential functions. These studies have shown that the use of connectives and narrative length significantly increase between the age of four to seven years (Kati $\&$ Kantzou, 2004). However, according to the same study frequency of use of adverbial clauses does not show a comparable increase during the same period. 
Since the present study primarily focuses on the development of character reference we compared two methods of story presentation in order to also evaluate the effects of method on accuracy of linguistic expressions according to each referential function. In previous studies the card method is reported to reinforce referent givenness more than the booklet method (Vion $\&$ Colas, 1999). It was further suggested that in the booklet method, 7 year olds tended to view each picture as an independent entity, while 11 year olds viewed it as a part of a whole. The card method promoted more referent givenness between 7-9 years. In a more recent study, Vion \& Colas (2005) observed more production of temporal \& causal links, which are additional markers of narrative coherence, in the card method.

\section{Research Questions}

The research goals of the present study are: a) to investigate the effects of the story presentation method (booklet vs card) on the linguistic variables of Reference, Loose Linking (e.g. 'and then...'), Coordination, Subordination and narrative Length in children from 3;6 to 6;6 years old and b) to examine possible interactions of narrative performance with short-term memory scores. We also investigated the question whether working memory could be shown to account for the differences in method presentation.

\section{Method}

Ninety-six typically developing Greek children divided in four age groups (3,6$6,6)$ participated in our study. The method used was an elicited story-telling task based on four different stories comprising four pictures each. Two methods of picture presentation were employed for narrative elicitation: a) the booklet and b) the card method. In the booklet method each picture is presented in a single page, while in the card method all pictures forming a story sequence appear on one page.

Three memory tasks were also administered for independent measurements of verbal memory abilities in order to examine possible relations between narrative performance and attention resources. Specifically, the Digit Span Task

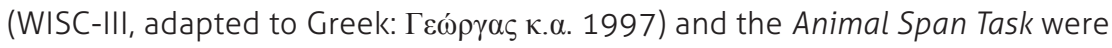
employed, (adapted to Greek from the Turkish original (Aksu-Koc (2009)), which test short working memory. We also administered the sentence repetition task of the DVIO test (Stavrakaki \& Tsimpli, 2000), which tests accuracy of recall of various linguistic structures. 


\section{Predictions}

The method of presentation is predicted to affect narrative coherence markers, i.e. coordination, subordination and length of narration, since there may be different strategies of constructing episodes in the booklet, as opposed to the card method. Moreover, maintaining reference may involve increased use of pronominals in the card method assuming that this method promotes referent givenness more, according to previous studies (Vion \& Colas, 1999). On the other hand, differences in memory scores among children may facilitate narrative production only in the booklet method, since the child does not view the complete story at once and has to rely on memory to construct the story episodes. Irrespective of method, the development of reference is expected around $4 ; 6$, with character maintenance being more adult-like earlier than character introduction (cf. Hickman et al, 1996; Wang \& Johnston, 2003). Accordingly, definiteness is expected to be more prominent in use by younger children than indefiniteness. Finally, memory is predicted to be a positive indicator of good narrative performance in the production of character maintenance and shift.

\section{Results}

The results of the study are presented for the tested variables both per method and irrespective of the method of story presentation.

Considering the method of presentation, our results for character introduction (Figure 1) show significantly enhanced performance in the booklet method only in the group of 4;6 year old children $\left(x^{2}=21.333, \mathrm{df}=1, \mathrm{p}=.000\right)$.

Developmentally, there is a significant change between the $3 ; 6$ and the $5 ; 6$ groups $\left(x^{2}=3.802, d f=1, p=.051\right)$ and between the $4 ; 6$ and the $6 ; 6$ year old children $\left(x^{2}=6.641, d f=1, p=.010\right)$.

Irrespective of method of presentation (Figure 2), as predicted there is a significant development between the ages of $4 ; 6$ and $5 ; 6\left(x^{2}=8.277, d f=1\right.$, $p=.004)$ for the function of referent introduction. Within-group performance is significantly more target than non-target like for all groups tested $\left(3 ; 6: x^{2}=4.667\right.$, $d f=1, p=.031 ; 4 ; 6: x^{2}=18.305, d f=1, p=.000 ; 5 ; 6: x^{2}=64.076, d f=1, p=.000 ; 6 ; 6$ : $\left.x^{2}=68.283, d f=1, p=.000\right)$.

Reference maintenance (Figure 3) with the use of a definite nominal is significantly more target-like in the booklet method in the youngest group $\left(x^{2}=18.864, d f=1, p=.000\right)$, while the 5;6 year olds preferred the card method $\left(x^{2}=10.777, d f=1, p=.001\right)$. Developmentally, there are significant changes up to $5 ; 6$ years $\left(3 ; 6\right.$ vs. $4 ; 6: x^{2}=6.079, \mathrm{df}=1, p=.014 ; 4 ; 6$ vs. $\left.5 ; 6: x^{2}=12.685, \mathrm{df}=1, p=.000\right)$.

On the other hand, irrespective of method and across age groups, there is development of maintenance from $3 ; 6$ to $4 ; 6\left(x^{2}=12.193, \mathrm{df}=1, p=.000\right)$ and 


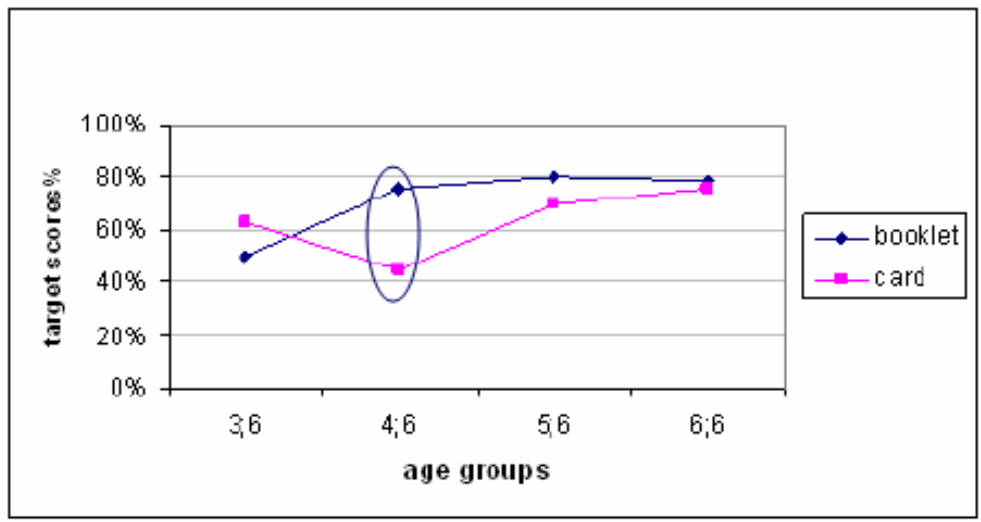

Figure 1. Use of indefinite NPs for character introduction per method

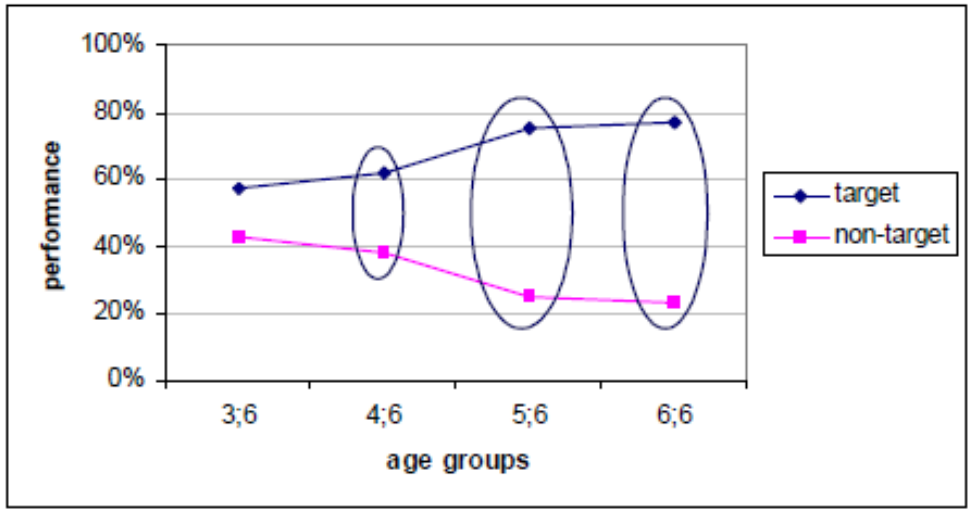

Figure 2. Use of indefinite NPs for character introduction across methods

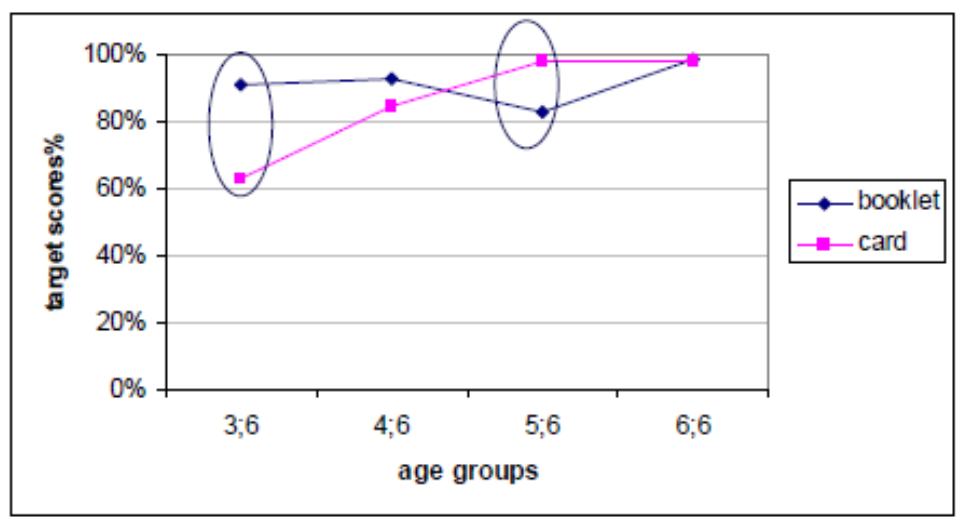

Figure 3. Use of definite NPs for character maintenance per method 
between the ages of $5 ; 6$ and $6 ; 6\left(x^{2}=9.085, d f=1, p=.003\right)$ (Figure 4). Withingroup data indicate that all groups produced significantly more target than non-target overt DPs to mark maintenance $\left(3 ; 6: x^{2}=47.867, d f=1, p=.000 ; 4 ; 6\right.$ : $x^{2}=10.625, d f=1, p=.000 ; 5 ; 6: x^{2}=118.140 d f=1, p=.000 ; 6 ; 6: x^{2}=156.568, d f=1$, $\mathrm{p}=.000)$.

Maintenance with the use of a null pronoun shows a developmental trend up to $5 ; 6$ years $\left(3 ; 6\right.$ vs $4 ; 6: x^{2}=5.505, d f=1, p=.019 ; 4 ; 6$ vs. $5 ; 6: x^{2}=4.050, d f=1$, $p=.044)$. All groups distinguish between ambiguous and unambiguous null pronoun uses $\left(3 ; 6: x^{2}=5973, d f=1, p=.015,4 ; 6: x^{2}=40.055, d f=1, p=.000,5 ; 6\right.$ : $x^{2}=84344, d f=1, p=.000,6 ; 6: x^{2}=81.000, d f=1, p=.000$ ) (Figure 5). The method of story presentation did not affect performance on pronominal use in any group, contrary to the prediction that the card method would promote referent givenness more than the booklet method.

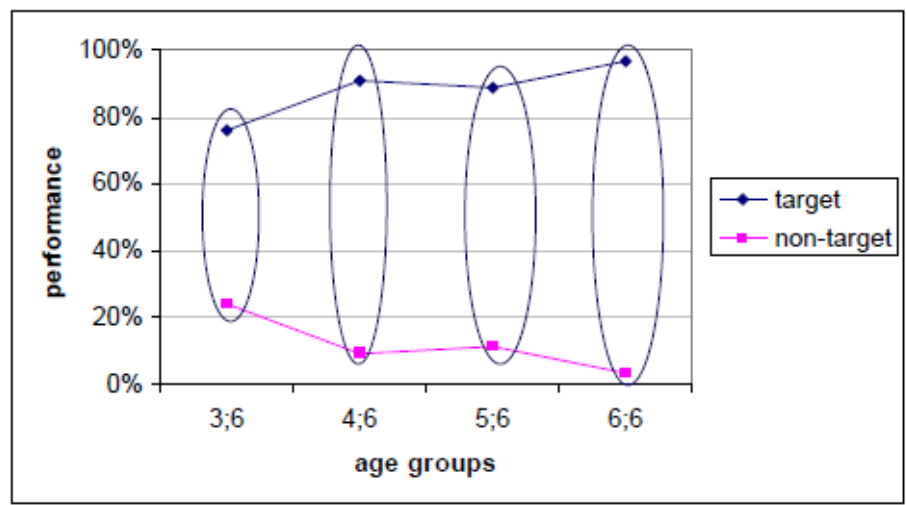

Figure 4. Use of definite NPs for character maintenance

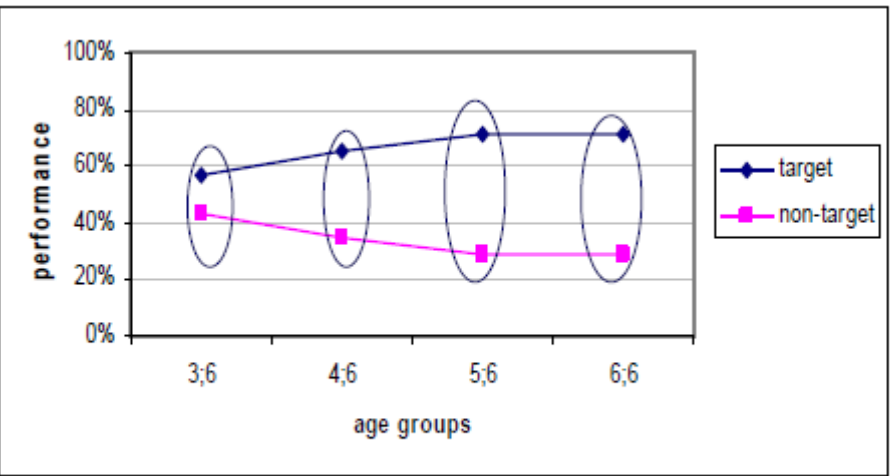

Figure 5. Appropriate and inappropriate (ambiguous) use of null pronouns for character maintenance across methods 
Maintenance with a null pronominal is not significantly better than the use of indefinite DPs for character introduction. As predicted maintenance and definiteness is achieved more accurately than reference introduction only when expressed with a DP $\left(3 ; 6: x^{2}=14.434, d f=1, p=.000 ; 4 ; 6: x^{2}=38.908\right.$, $d f=1, p=.000 ; 5 ; 6: x^{2}=13.232, d f=1, p=.000 ; 6 ; 6: x^{2}=31.420, d f=1, p=.000$ ) (Figure 6).

Between group comparisons do not reveal any significant changes in the pattern of acquisition of the introduction of a referent when compared to the maintenance of a referent. In character maintenance, definite nominals are significantly more accurately produced than pronominals in all groups tested (Figure 7).

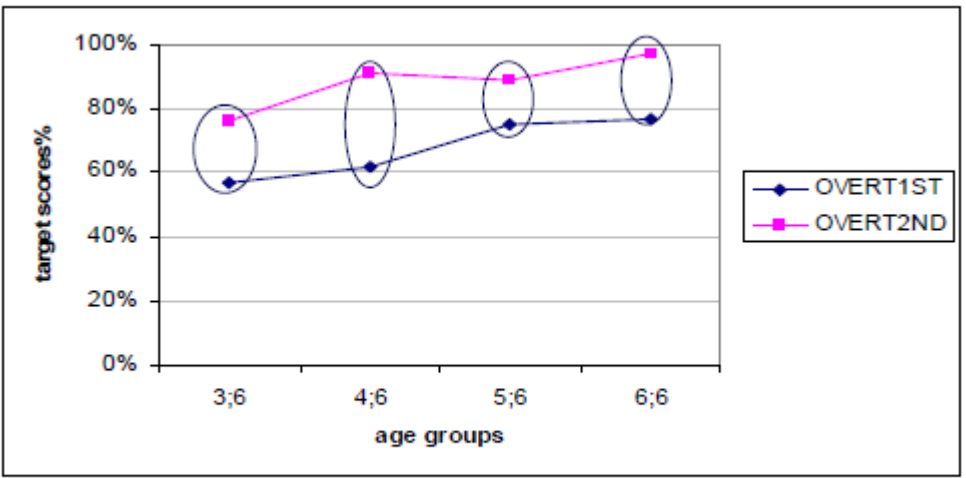

Figure 6. Comparison between accurate production of DPs for character introduction vs. character maintenance

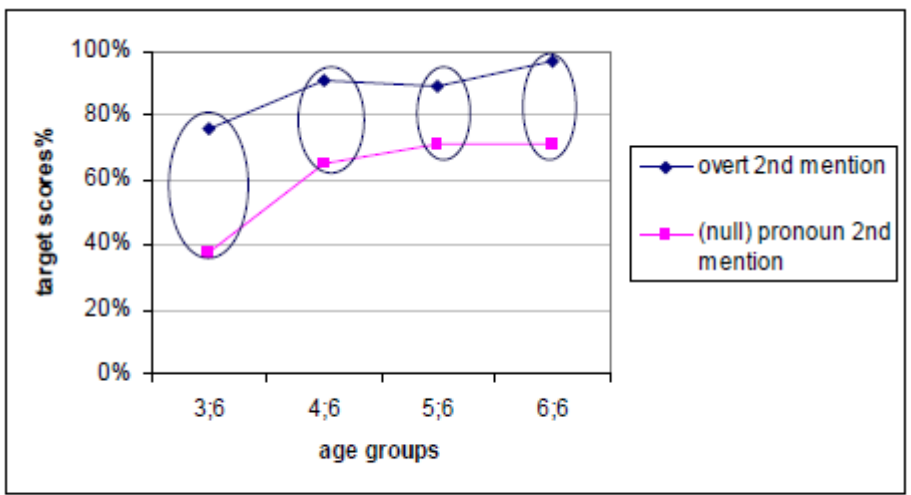

Figure 7. Character maintenance with nominal vs. pronominal DPs 
Within group comparisons revealed a high significance in the ease of target production of nominal DPs when compared to pronominal DPs $\left(3 ; 6: x^{2}=19.060\right.$, $d f=1, p=.000 ; 4 ; 6: x^{2}=38.673, d f=1, p=.000 ; 5 ; 6: x^{2}=24.949, d f=1, p=.000 ; 6 ; 6:$ $x^{2}=52.910, d f=1, p=.000$ ).

Turning to the other properties of narratives examined, length of the narrative (Figure 8) which was measured on the basis of the verbs (clauses) used, revealed a developmental trend between the ages of $3 ; 6$ and $4 ; 6\left(x^{2}=28.351, d f=1\right.$, $p=.000)$ and between the ages of $5 ; 6$ and 6;6 $\left(x^{2}=10.343, d f=1, p=.000\right)$. This result is in line with the results of previous studies (cf. Kati \& Kantzou, 2004) and justifies our hypothesis that there is a development in the number of clauses used in narratives.

Considering the length of narrative per method (Figure 9), in the booklet method children engaged in longer narratives in the 4;6 $\left(x^{2}=43.668, d f=1\right.$, $p=.000)$ and the $5 ; 6$ year old groups $\left(x^{2}=110.124, d f=1, p=.000\right)$, but there was an advantage of the card method in the oldest group of $6 ; 6$ year olds $\left(x^{2}=6.016\right.$, $\mathrm{df}=1, \mathrm{p}=.014$ ).

A developmental trend in the production of loose linking structures (Figure 10) was observed between the ages ages $3 ; 6$ and $4 ; 6\left(x^{2}=6.016, d f=1, p=.014\right)$ and between the 5;6 and 6;6 year olds $\left(x^{2}: 16.206, d f=1, p=.000\right)$.

The frequency of use of loose linking structures does not seem to be affected by the method of story presentation.

Regarding the use of coordination by method of story presentation (Figure 11) we notice a developmental change affecting coordination between $3 ; 6$ and $4 ; 6$ year olds $\left(x^{2}=17.126, d f=1, p=.000\right)$. Within group differences reveal preference for the booklet method for all groups except the youngest. Preference is for the booklet method for the $4 ; 6$ and the $5 ; 6$ group $\left(4 ; 6: x^{2}=.26 .472, d f=1\right.$, $\left.p=.000 ; 5 ; 6: x^{2}=7.298, d f=1, p=.007\right)$ while the $6 ; 6$ year olds preferred the card

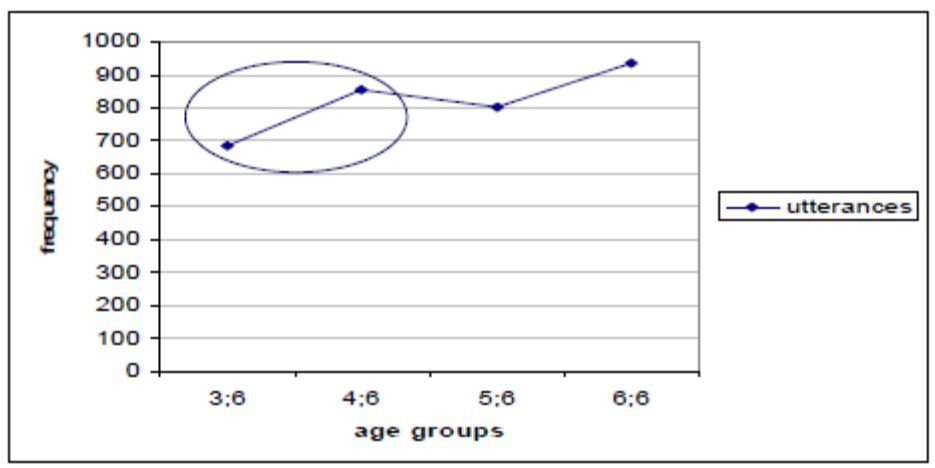

Figure 8. Length of narrative (no of verb/clauses) across methods 
method $\left(x^{2}=4.489, d f=1, p=.034\right)$. The results showing enhanced production of coordination in the booklet method are in line with previous studies that report less referent givenness in the booklet method when compared to the card method. Referent givenness may promote more the production of subordination. Irrespective of method, coordination develops up to $5 ; 6\left(3 ; 6\right.$ vs. $4 ; 6: x^{2}=17.526$, $d f=1, p=.000 ; 4 ; 6$ vs. 5;6: $x^{2}=9.648, d f=1, p=.000$ ).

As regards subordinate structures the results were differentiated by method only for the oldest group, who used more subordination in the card method $\left(x^{2}=4314, d f=1, p=.038\right)$ (Figure 13).

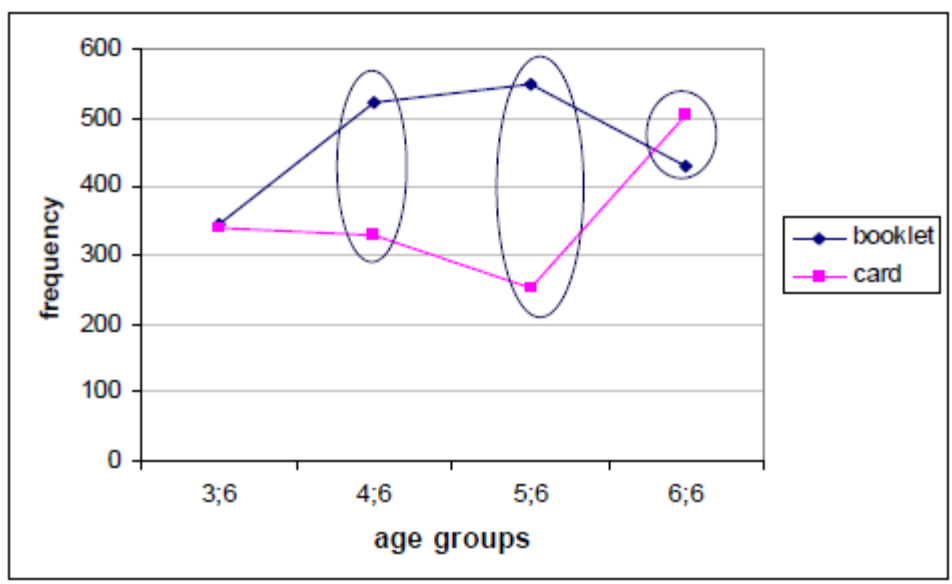

Figure 9. Length of narrative (number of verbs/clauses) per method

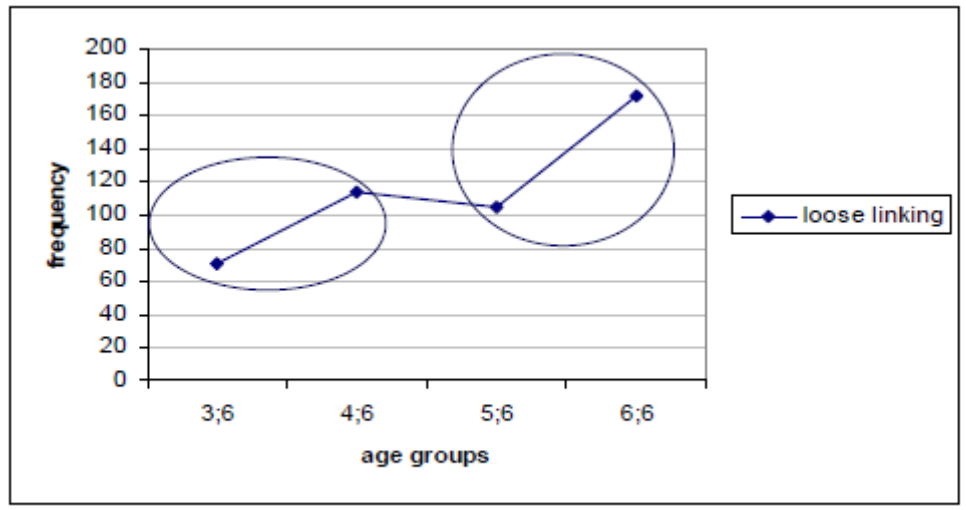

Figure 10. Frequency of loose linking structures 


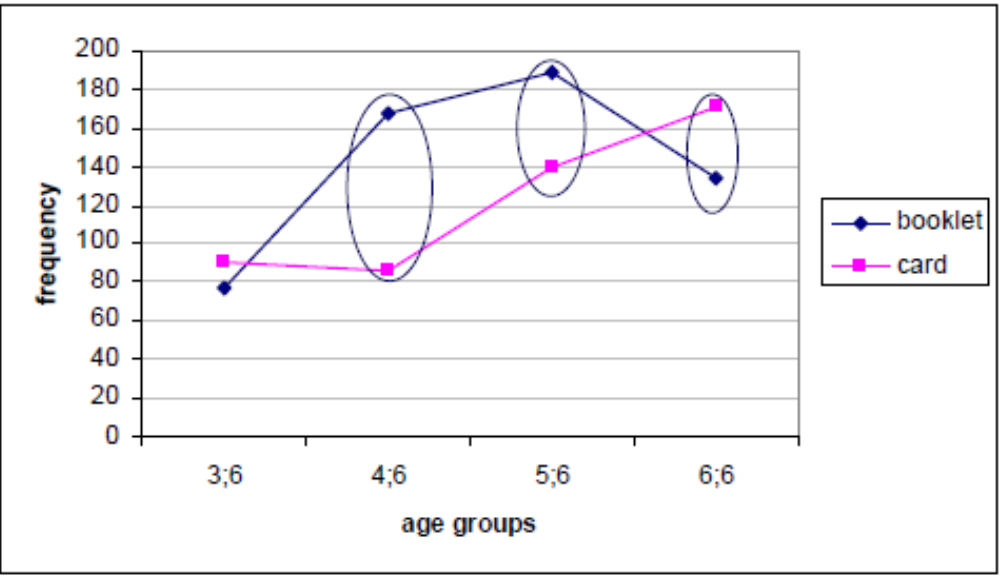

Figure 11. Frequency of coordinate structures per method

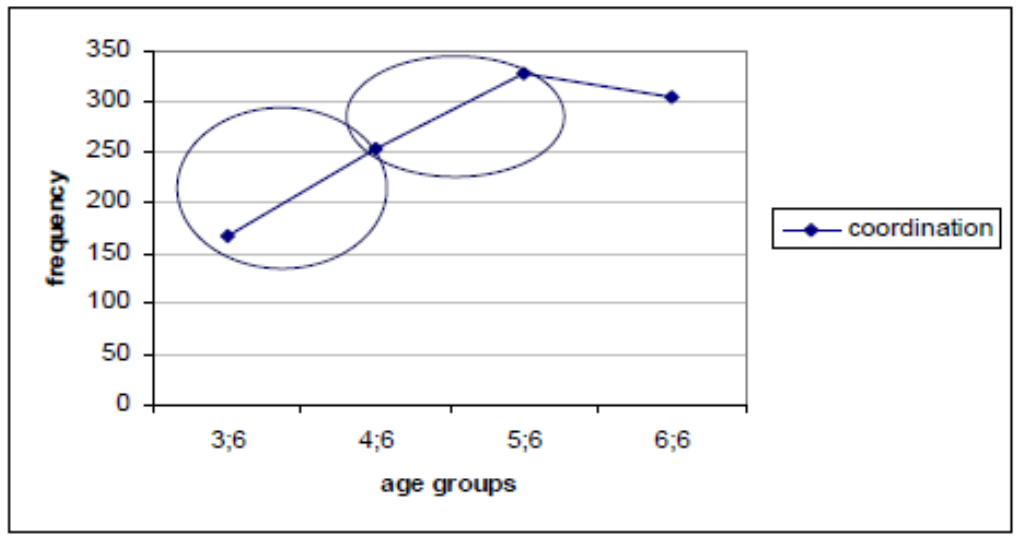

Figure 12. Frequency of coordinate structures across methods

Embedded structures, as are the subordinate structures means that referent givenness is well established. This result is in line with previous studies (Vion $\&$ Colas, 1999) reporting that the card method reinforces definiteness between 7-9 years old.

As regards subordination irrespective of method, it develops up to $4 ; 6$ $\left(x^{2}=11.082, d f=1, p=.000\right)$. Then there are no significant differences with the older groups (Figure14).

As for the priority in the development of the coordinate structures over the subordinate, the $4 ; 6$ age group seems to be showing a clear developmental 


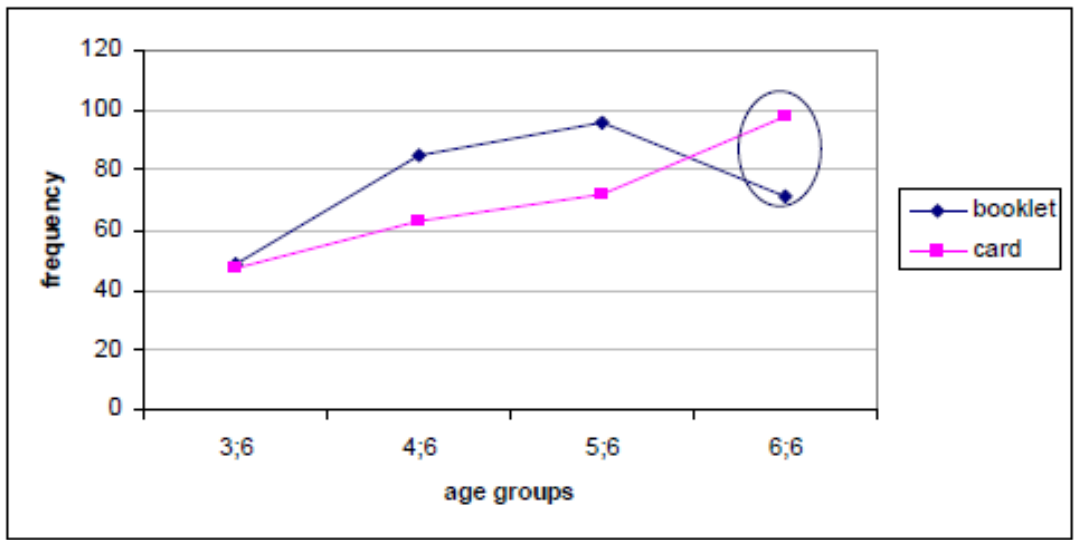

Figure 13. Frequency of subordinate structures per method

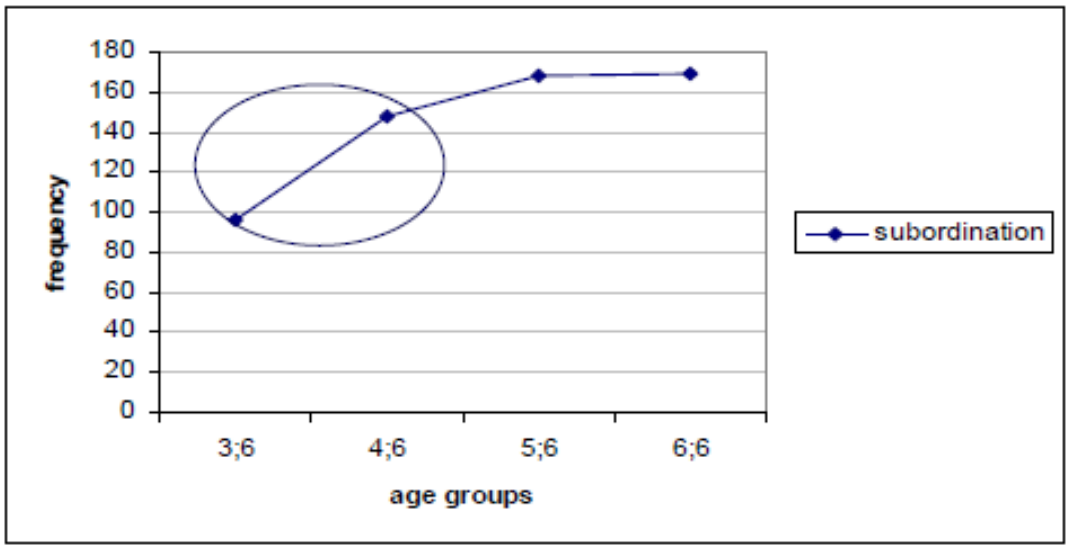

Figure 14. Frequency of subordinate structures across methods

turning point for both coordination and subordination. As was predicted, the comparison of the frequency of production of the coordinate vs. the subordinate structures (Figure 15) within groups revealed that all groups produced more coordinate than subordinate structures $\left(3 ; 6: x^{2}=6.630\right.$, $d f=1, p=.000 ; 4 ; 6: x^{2}=7.476, d f=1, p=.006 ; 5 ; 6: x^{2}=16.399, d f=1, p=.000 ;$ $\left.6 ; 6: x^{2}=6.770, d f=1, p=.000\right)$. Between groups there were not significant developmental changes in the pattern of production. Studies for other languages also support the precedence of coordination over subordination (cf. de Villiers, 1982). 


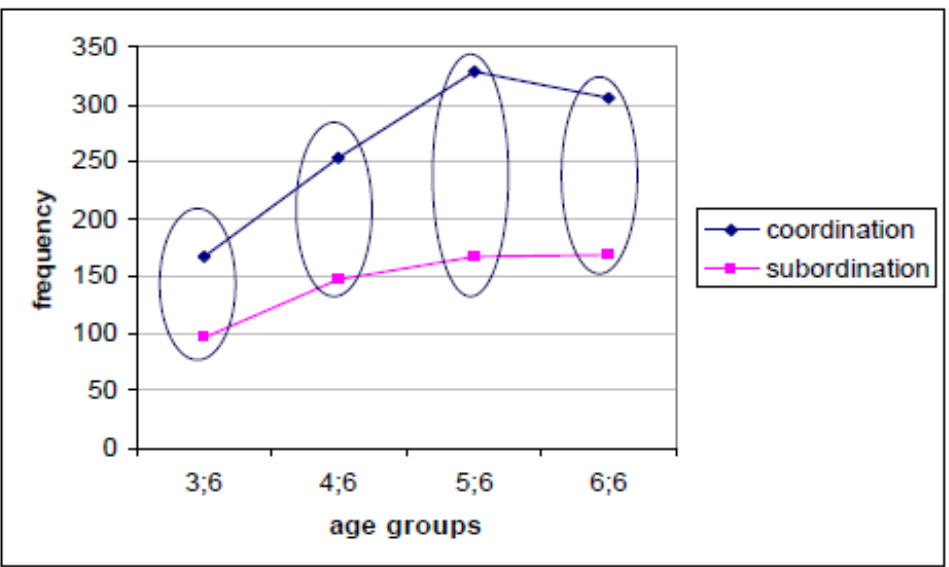

Figure 15. Frequency of coordinate vs. subordinate structures

Finally, to examine possible links between good narrative ability and memory, children were tested with two short memory tests, the Digit Span Task and the Animal Span Task (Table 1) and the sentence repetition DVIO test (Table 2).

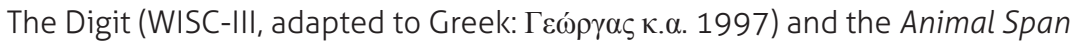
Task (adapted to Greek from the Turkish original (Aksu-Koc, 2009)), measure short-term memory involving forward and backward digit recall and similar patterns with animal names respectively. In the table below we present mean, upper and lower scores per age group.

Table 1.

Scores from the Short Memory Tests

\begin{tabular}{|l|l|l|l|}
\hline & Digit Span Task & & \\
\hline Age groups & Mean scores & Upper scores & Lower scores \\
\hline $\mathbf{3 ; 6}$ & 4.33 & 7.39 & 1.27 \\
\hline $\mathbf{4 ; 6}$ & 6.04 & 10.12 & 1.96 \\
\hline $\mathbf{5 ; 6}$ & 7.83 & 11.15 & 4.51 \\
\hline $\mathbf{6 ; 6}$ & 8.57 & 12.47 & 4.67 \\
\hline & Animal Span Task & & \\
\hline & Mean scores & Upper scores & Lower scores \\
\hline $\mathbf{3 ; 6}$ & 5.33 & 8.75 & 1.91 \\
\hline $\mathbf{4 ; 6}$ & 6.71 & 10.13 & 3.29 \\
\hline $\mathbf{5 ; 6}$ & 8.05 & 11.17 & 4.93 \\
\hline $\mathbf{6 ; 6}$ & 8.27 & 10.77 & 5.77 \\
\hline & & & \\
\hline
\end{tabular}


Table 2.

Scores from the DVIO sentence repetition task

\begin{tabular}{|l|l|l|l|}
\hline & DVIO & \multicolumn{2}{|l|}{} \\
\hline Age groups & Raw numbers & $\%$ & Norms \\
\hline $3 ; 6$ & $41 / 48$ & $85 \%$ & 39.4 \\
\hline $\mathbf{4 ; 6}$ & $44 / 48$ & $92 \%$ & 39.4 \\
\hline $\mathbf{5 ; 6}$ & $47 / 48$ & $98 \%$ & 41.8 \\
\hline $\mathbf{6 ; 6}$ & $25 / 30$ & $83 \%$ & - \\
\hline
\end{tabular}

The results of the two tasks are comparable. The Animal Span Task though reached slightly higher mean scores within all age groups tested.

As for the sentence repetition task (Table 2 ) results of the $3 ; 6$ to $5 ; 6$ groups were within the standardized norms of the DVIO preschoolers Test (Stavrakaki \& Tsimpli, 2000). Additionally, significant difference is found in the comparison between the 3;6 and the 5;6 year olds $\left(x^{2}=14.909, d f=1, p=.027\right)$.

As for the 6;6 year olds notice that the scale is different. This group took the school age edition of the Test for which there are no standardized norms. Therefore, no direct comparisons can be made between the oldest group of children and the rest of the groups.

The results in the three memory tests presented above were compared to performance in the narrative task. The ability to use the appropriate DP to mark reference was examined in relation to memory scores. The comparison revealed that children with high memory scores seemed to show better narrative performance in the target use of nominals and pronominals to introduce and maintain reference.

In a first attempt to relate memory with referential functions Figure 16 shows the 5;6 group's performance in the Animal Span Task. Each point stands for each child's performance. The $8^{\text {th }}$ dot is the case of a child who scored very low in the task. His performance lies in the lower outliers. On the other hand, the $11^{\text {th }}$ dot presents the score of a child with high memory scores belonging to the upper outliers.

What is of interest is to see whether low or high level performance in the memory task influences results in referential scores. In figure 17 we present the $5 ; 6$ group's scores in the function of referent maintenance with a nominal or a pronominal DP. We observe that the scores of both the $2^{\text {nd }}$ and the $11^{\text {th }}$ dot which correspond to the same children as in Figure 16 are very high.

In particular, the $11^{\text {th }}$ child who had a high memory score also had a very high target performance in referent maintenance. What can be implied from this first attempt to relate memory with reference is that good memory ability boosts narrative skills but it does not seem to be a necessary condition for good narrative ability. 


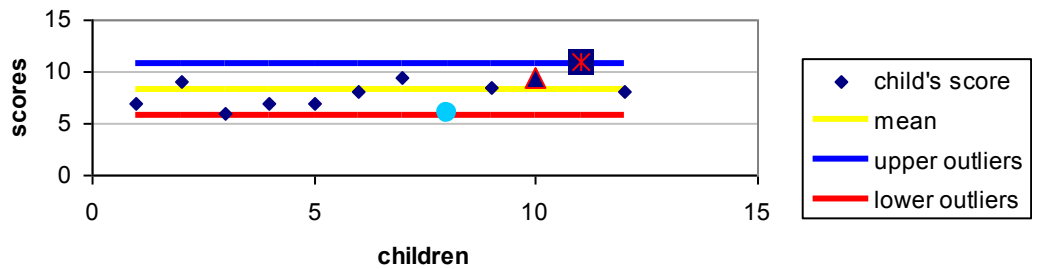

Figure 16. Results of the Animal Span Task

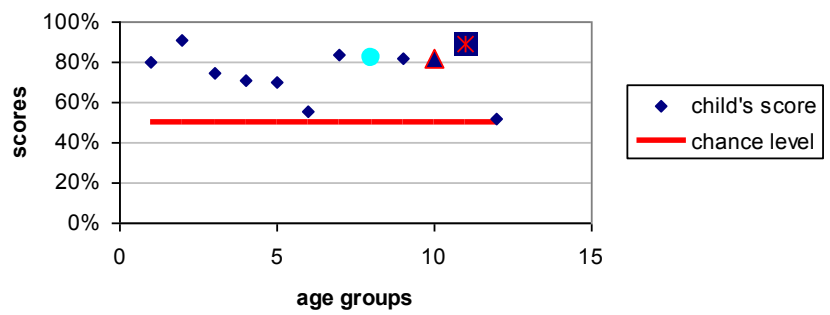

Figure 17. Target performance in maintenance with an overt DP

We assume that the reason why the memory test results were not illuminating with respect to their role in narrative discourse development has to do with the fact that what was tested with the Digit Span Task was STM (short term memory). A test measuring working memory at the sentence level would probably be more revealing in this respect.

\section{Discussion}

For all groups except the youngest, referent maintenance was easier when realized with an overt nominal, while referent introduction as well as maintenance with a null or an overt pronominal subject were less frequently used. The difference between lexical DPs in introduction and maintenance could be associated with the delay in the development of indefinites, possibly due to their more elaborate semantics/pragmatics. As a result, indefinite productions appear to be better markers of narrative development (see also Schneider and Hayward, 2010). That pronouns are more demanding than definite noun phrases has also been shown in adult data. Arnold and Griffin (2007) found that adults too prefer to use lexical DPs over pronouns even when gender differences in characters 
would make pronominal use an unambiguous marker of reference. Pronominal use is related to discourse anaphora and therefore, their target production is considered more complex and presupposes more advanced pragmatics or more resources in information processing and integration.

The different performance of the 4;6 age group indicates that this age is critical for the development of narratives since linguistic variables associated with it, develop at that stage. In particular, length of narration measured in number of verbs used, loose linking, coordination and subordination show significant development at 4;6. Coordinate structures are more frequent than Subordinate ones, however, for all groups tested.

There is not a clear effect of method on the development of Reference, but, overall, the booklet method elicits better performance up to 6;6 with respect to coordination and number of verbs used. The oldest group had a better performance in the card method for all linguistic properties examined except for referential functions.

With respect to memory ability, low memory scores did not appear to entail low linguistic scores. However, STM (Short-Term Memory) is different from Working Memory (Baddeley, 2007) and possibly, narrative production would be sensitive to working memory scores (attentional control and resource allocation than phonological short term memory) (cf. Montgomery et al 2009 for such results on narrative comprehension).

\section{Conclusion}

Our study reveals that of the various aspects of Reference examined, introduction and pronominal use for Maintenance are slower in development than Maintenance with the use of full noun phrases. Accordingly, the referential function of Character Introduction seems a more reliable marker of the development of referential abilities in narratives. The method of story presentation affects quantity more than quality of narrative production. Memory span is an indicator of narrative ability only for older children. 


\section{References}

Arnold, J. and Z. Griffin. 2007. The effect of additional characters on choice of referring expression: Everyone counts. Journal of Memory and Language 56, 521536.

Baddeley, A. 2007. Working memory, thought and action. Oxford: Oxford University Press.

Bower, G.H. and D.G. Morrow. 1990. Mental models in narrative comprehension. Science 247, 44-48.

Chafe, W. 1976. Givenness, contrastiveness, definiteness, subjects, topics and point of view. In C.N. Li (ed.), Subject and topic. New York: Academic Press.

De Villiers, J. 1982. The development of sentence coordination. Language Development Vol.1: Syntax and Semantics.

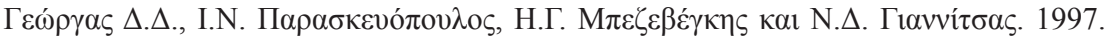

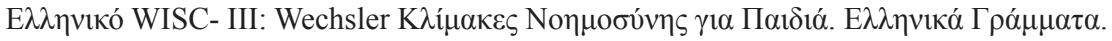

Hickmann, M. 1996. Information Status and Grounding in Children's Narratives: A crosslinguistic Perspective. Processing Interclausal Relationships. Studies in the Production and Comprehension of Text, 221-243.

Hickmann M. and H. Hendriks. 1999. Cohesion and Anaphora in Children's Narratives: a comparison of English, French, German and Mandarin Chinese. Journal of Child Language 26, 419-452.

Hickmann, M., H. Hendriks, F. Roland and J. Liang. 1996. The marking of new information in children's narratives: a comparison of English, French, German and Mandarin Chinese. Journal of Child Language 23, 591-619. 
Hickmann, M. and P. Schneider. 1993. Children's ability to restore the referential cohesion of stories. First Language 13, 169-202.

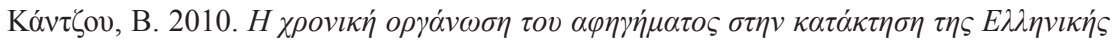

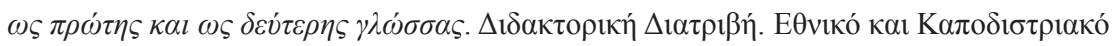

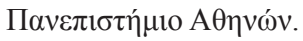

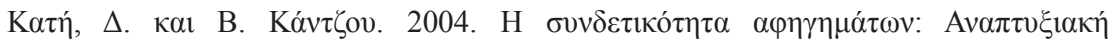

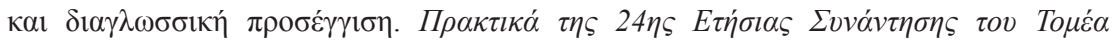

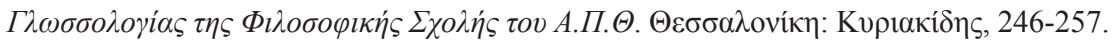

Stavrakaki, S. and I.M. Tsimpli. 2000. Diagnostic verbal IO test for school and preschool children: Standardization, statistical analysis, and psychometric properties. Proceedings of the 8th conference of the Panhellenic Association of Speech and Language Therapists. Athens: Ellinika Grammata, 95-106.

Vion, M. and A. Colas. 1999. Expressing Coreference in French: Cognitive Constraints and Development of Narrative Skills. Journal of Psycholinguistic Research 28 (3). 
Major Trends in Theoretical and Applied Linguistics 